\title{
3D Network Structural Poly (Aryl Ether Ketone)- Polybenzimidazole Polymer for High-Temperature Proton Exchange Membrane Fuel Cells
}

\author{
Junqiao Jiang, ${ }^{1}$ Erli Qu, ${ }^{1}$ Min Xiao $\mathbb{D}^{1},{ }^{1}$ Dongmei Han, ${ }^{1,2}$ Shuanjin Wang $\mathbb{D}^{1}$ \\ and Yuezhong Meng $\mathbb{B}^{1}$ \\ ${ }^{1}$ The Key Laboratory of Low-Carbon Chemistry \& Energy Conservation of Guangdong Province, State Key Laboratory of \\ Optoelectronic Materials and Technologies, School of Materials Science and Engineering, Sun Yat-sen University, \\ Guangzhou 510275, China \\ ${ }^{2}$ School of Chemical Engineering and Technology, Sun Yat-sen University, Zhuhai 519082, China
}

Correspondence should be addressed to Shuanjin Wang; wangshj@mail.sysu.edu.cn and Yuezhong Meng; mengyzh@mail.sysu.edu.cn

Received 4 June 2020; Revised 20 July 2020; Accepted 29 July 2020; Published 14 August 2020

Academic Editor: Sagar Roy

Copyright (C) 2020 Junqiao Jiang et al. This is an open access article distributed under the Creative Commons Attribution License, which permits unrestricted use, distribution, and reproduction in any medium, provided the original work is properly cited.

Poor mechanical property is a critical problem for phosphoric acid-doped high-temperature proton exchange membranes (HTPEMs). In order to address this concern, in this work, a 3D network structural poly (aryl ether ketone)-polybenzimidazole (PAEK-cr-PBI) polymer electrolyte membrane was successfully synthesized through crosslinking reaction between poly (aryl

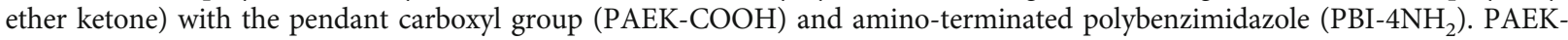
$\mathrm{COOH}$ with a poly (aryl ether ketone) backbone endows superior thermal, mechanical, and chemical stability, while $\mathrm{PBI}^{-4 \mathrm{NH}_{2}}$ serves as both a proton conductor and a crosslinker with basic imidazole groups to absorb phosphoric acid. Moreover, the composite membrane of PAEK-cr-PBI blended with linear PBI (PAEK-cr-PBI@PBI) was also prepared. Both membranes with a proper phosphoric acid (PA) uptake exhibit an excellent proton conductivity of around $50 \mathrm{mS} \mathrm{cm}^{-1}$ at $170^{\circ} \mathrm{C}$, which is comparable to that of the well-documented PA-doped PBI membrane. Furthermore, the PA-doped PAEK-cr-PBI membrane shows superior mechanical properties of $17 \mathrm{MPa}$ compared with common PA-doped PBI. Based upon these encouraging results, the as-synthesized PAEK-cr-PBI gives a highly practical promise for its application in high-temperature proton exchange membrane fuel cells (HT-PEMFCs).

\section{Introduction}

Proton exchange membrane fuel cells (PEMFCs) have drawn much attention as clean power generation devices due to their many attractive features, such as high efficiency, high power density, and environmental friendliness for potential application as power sources in stationary transportation and portable devices [1-5]. Proton exchange membranes (PEMs) are key components of the PEMFCs, which play the main role of proton transport and fuel isolation. Compared with conventional low-temperature PEMFCs, hightemperature PEMFCs (HT-PEMFCs) operate at above $100^{\circ} \mathrm{C}$, which made it possess many advantages, such as simple water and heat management, high CO tolerance, and less dependence on platinum catalysts [6-8].

Among all the types of HT-PEMs, phosphoric aciddoped polybenzimidazole (PA-PBI) membranes have been considered to be the most promising candidates for a hightemperature proton exchange membrane owing to its good chemical and thermal stability and excellent proton conductivity under anhydrous conditions at high temperature [912]. In order to obtain high proton conductivity, it is necessary to dope an excess amount of phosphoric acid (PA) in the membrane [13]. However, due to the strong plasticization 


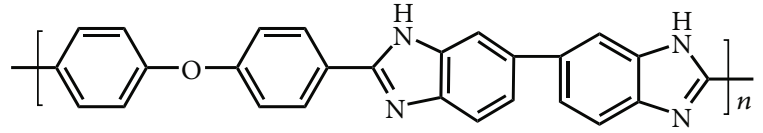

Figure 1: The molecular structure of poly $\left(4,4^{\prime}\right.$-(diphenyl ether)5,5' -bibenzimidazole) (PBI).

of PA molecules, high proton conductivity is usually at the expense of the mechanical strength of the membrane [1417]. Besides, the preparation of a high-strength PA-PBI membrane requires high molecular weight of PBI, which exhibits poor solubility in organic solvents and makes it fairly hard to prepare uniform casting solution [18]. Therefore, to realize high-performance HT-PEMs and high-efficiency HT-PEMFCs, it is one of the important issues to settle the balance between proton conductivity and mechanical properties of phosphoric acid-doped polymer membranes.

In fact, several strategies have been proposed to deal with the issue. Crosslinking is considered an effective strategy to enhance the properties of PA-doped membranes for HTPEMFCs [19-23]. In the past few decades, a variety of crosslinkers have been widely studied, including small molecular and macromolecular crosslinkers. Small molecular crosslinkers such as epoxides [24, 25] and halides [26-28] are more frequently used for the improvement of the membrane properties. Compared with small molecular crosslinkers, macromolecular crosslinkers will give higher overall performance to HT-PEMs. Recently, Yang et al. [29] studied the covalently crosslinking PBI membrane using chloromethyl polysulfone as the macromolecular crosslinker. Their results show that the properties of the crosslinked membranes with high PA doping level are almost unchanged during the test. In addition, other macromolecular crosslinkers such as poly (vinyl benzyl chloride) [30] and bromomethylated poly (aryl ether ketone) [31] have also been adopted to prepare crosslinked PBI membranes. Unfortunately, most of these methods are based on the sacrifice of $\mathrm{N}-\mathrm{H}$ sites on the imidazole ring of the PBI main chain, which ultimately impedes the absorption of phosphoric acid and proton transport [32]. All in all, it is an urgent demand to design a reasonable polymer framework and a suitable covalent crosslinker to satisfy the actual requirements of HT-PEMs. To our knowledge, poly (aryl ether ketone) (PAEK) is extensively used in the preparation of various electrolyte membranes in fuel cells due to its good thermal, mechanical, and chemical stability [33-36].

In this work, we prepared a 3D network structural poly (aryl ether ketone)-PBI (PAEK-cr-PBI) through crosslinking reaction between $\mathrm{PAEK}$ with the pendant carboxyl group (PAEK-COOH) and amino-terminated imidazole (PBI$4 \mathrm{NH}_{2}$ ). For the purpose of enhancing the mechanical strength of a PA-doped membrane without the sacrifice of proton conductivity, a new crosslinker $\left(\mathrm{PBI}-4 \mathrm{NH}_{2}\right.$, polybenzimidazole terminated with amino groups) was designed and synthesized. This kind of crosslinked membrane gets rid of the binding of PBI as a polymer framework. Besides, poly (aryl ether ketone) has good thermal stability to meet the test requirements of HT-PEMFCs, and the $3 \mathrm{D}$ network structure of the membrane can maintain good mechanical properties after phosphoric acid doping. In addition, we also prepared the composite membrane PAEK-cr-PBI@PBI, which was obtained by blending PAEK-cr-PBI and PBI polymers. In order to better evaluate the performance of the assynthesized PAEK-cr-PBI and PAEK-cr-PBI@PBI membranes, we compared the well-documented PBI membrane with it. The properties of these membranes, including their solubility in common solvent, morphology analysis, thermal stability, oxidative stability, proton conductivity, and mechanical strength, were studied and compared.

\section{Experiment}

\subsection{Materials and Chemicals}

2.1.1. Materials. Poly (4,4'-(diphenyl ether)-5, $5^{\prime}$-bibenzimidazole) (PBI, $6000 \mathrm{~Pa} \cdot S)$ was obtained from Shanghai Shengjun Plastic Technology Co., Ltd. Figure 1 shows the molecular structure of PBI.

2.1.2. Chemicals. 4,4-Bis(4-hydroxyphenyl)-valeric acid (98\%), phosphorus pentoxide $\left(\mathrm{P}_{2} \mathrm{O}_{5}\right)$, polyphosphoric acid (PPA), phosphoric acid solution (85 wt\%), and 1-methyl-2pyrrolidinone (NMP) were obtained from Aladdin Chemistry Co. Ltd. 4,4' -Difluorobenzophenone (99\%), isophthalic acid (IPA), and 3,3'-diaminobenzidine (DAB, 97\%) were obtained from Shanghai Macklin Biochemical Co. Ltd. Potassium carbonate $\left(\mathrm{K}_{2} \mathrm{CO}_{3}\right)$, toluene, isopropyl alcohol, tetrahydrofuran (THF), and hydrochloric acid $(\mathrm{HCl})$ were purchased from Guangzhou Chemical Reagent Factory. Ammonia solution (25 wt\%) was purchased from Tianjin Fuyu Fine Chemical Co. Ltd.

\subsection{Synthesis}

2.2.1. Synthesis of PAEK-COOH. Poly (arylene ether ketone) with the pendant carboxyl group (PAEK-COOH) was synthesized via the step condensation polymerization $[33,37$, 38]. The synthetic pathway of PAEK-COOH is shown in Scheme 1(a); in a $250 \mathrm{~mL}$ three-neck round-bottom flask equipped with a magnetic stirrer, a condenser, a Dean-Stark trap, and a nitrogen inlet, 4,4-bis(4-hydroxyphenyl)-valeric acid $(2.86 \mathrm{~g}, 0.01 \mathrm{~mol})$ and $4,4^{\prime}$-difluorobenzophenone $(2.18 \mathrm{~g}, 0.01 \mathrm{~mol})$ were dissolved in $40 \mathrm{~mL}$ DMSO and $45 \mathrm{~mL}$ toluene. Then, $\mathrm{K}_{2} \mathrm{CO}_{3}(3.46 \mathrm{~g}, 0.025 \mathrm{~mol})$ was added to the reaction flask. Under an atmosphere of nitrogen, the mixture was heated to $145^{\circ} \mathrm{C}$ and maintained at this temperature for $4 \mathrm{~h}$ until the water was totally separated by means of a Dean-Stark trap using toluene. Then, the system temperature was elevated to $170^{\circ} \mathrm{C}$ to render polymerization for $22 \mathrm{~h}$.

Purification of the polymers was done by decantation of the supernatant from the reaction mixture after cooling to room temperature; then, $\mathrm{HCl}$ and $\mathrm{THF}$ were added at a ratio of $1: 4$; thus, the mixture was stirred until the solid polymer was completely dissolved. After the stirring, the orangecolored polymer layer floating on the top of the liquid phase was collected. The PAEK-COOH solution in THF (orangecolored polymer layer) was precipitated by dropping it into $500 \mathrm{~mL}$ of isopropyl alcohol in a $1 \mathrm{~L}$ beaker. The obtained white polymer was washed with isopropyl alcohol, followed 


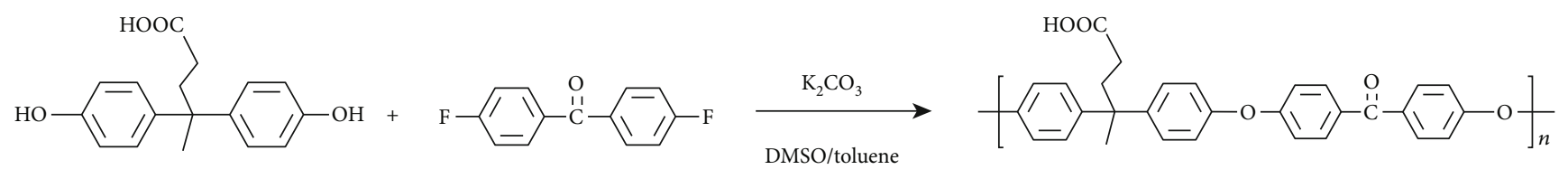

PAEK-COOH

(a)

2<smiles>Nc1ccc(-c2ccc(N)c(N)c2)cc1N</smiles>

DAB<smiles>O=C(O)c1cccc(C(=O)O)c1</smiles>

IPA

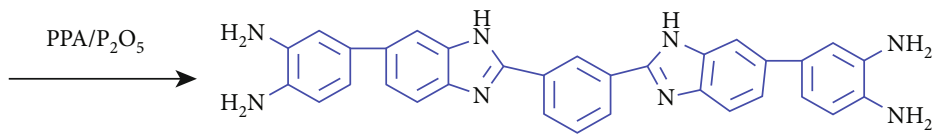

PBI-4NH

(b)

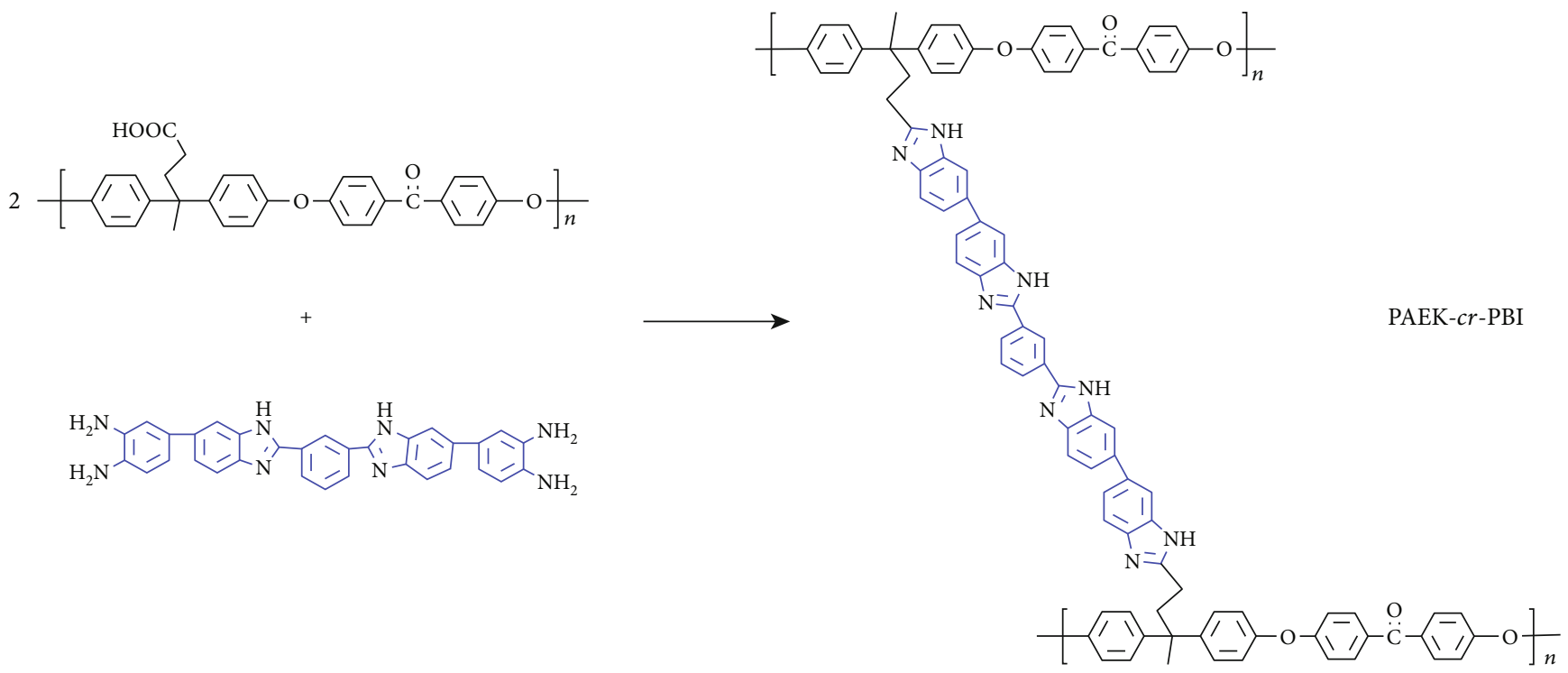

(c)

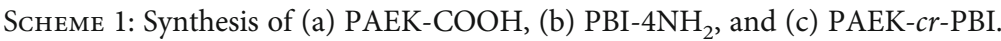

by deionized water. Then, the purified product, PAEK$\mathrm{COOH}$, was dried in a $100^{\circ} \mathrm{C}$ dry oven for $24 \mathrm{~h}$.

2.2.2. Synthesis of the Crosslinker $\left(\mathrm{PBI}-4 \mathrm{NH}_{2}\right)$. The amineterminated polybenzimidazole $\left(\mathrm{PBI}-4 \mathrm{NH}_{2}\right)$ was synthesized by the condensation reaction of $3,3^{\prime}$-diaminobenzidine (DAB) with isophthalic acid (IPA) in polyphosphoric acid (PPA) $[39,40]$, as shown in Scheme $1(\mathrm{~b})$. In a $100 \mathrm{~mL}$ dry three-neck flask equipped with a nitrogen inlet and a nitrogen outlet, $27 \mathrm{~g}$ of PPA and $7 \mathrm{~g}$ of phosphorus pentoxide were heated at $120^{\circ} \mathrm{C}$ under nitrogen flow and mechanically stirred about $4 \mathrm{~h}$ till a clear solution was observed. After cooling to room temperature, $\mathrm{DAB}(1.2856 \mathrm{~g}, 6 \mathrm{mmol})$ and IPA $(0.4985 \mathrm{~g}, 3 \mathrm{mmol})$ were added; then, the reaction mixture was mechanically stirred, slowly heated to $190^{\circ} \mathrm{C}$, and kept at this temperature for $20 \mathrm{~h}$. After cooling to about $80^{\circ} \mathrm{C}$, the viscous solution was slowly poured into the ice deionized water and then was neutralized to $\mathrm{pH} 7$ with dilute solution of ammonium hydroxide solution ( $5 \mathrm{wt} \%)$. The product was filtered and washed with deionized water several times and dried in a freeze dryer for 2 days at minus $60^{\circ} \mathrm{C}$ to remove the residual solvents completely.

\subsection{Preparation of Membranes}

2.3.1. Preparation of the PAEK-cr-PBI Membrane. The synthesis route of PAEK-cr-PBI is shown in Scheme 1(c), and the PAEK-cr-PBI membrane was fabricated by a solution casting method, as shown in Scheme 2. The calculated result of the carboxyl equivalent in PAEK-COOH is $2.15 \mathrm{mmol} / \mathrm{g}$. Firstly, PAEK-COOH (300.0 mg) was dissolved in 2-3 mL 1-methyl2-pyrrolidinone (NMP) to form a uniformly transparent solution. Then, the PBI- $4 \mathrm{NH}_{2}(168.6 \mathrm{mg}$, the molar ratio of diamino to carboxyl is $1: 1$ ) was dissolved completely in $2 \mathrm{~mL}$ NMP. The total polymer concentration was controlled to be $8 \sim 15 \%(w / v)$. After that, the solution of PBI- $4 \mathrm{NH}_{2}$ was added dropwise into the solution of PAEK-COOH in NMP and then stirred for $4 \mathrm{~h}$ to obtain a uniform solution. The resulting polymer solution was cast onto a clean glass plate followed by heating at $80^{\circ} \mathrm{C}$ for $5 \mathrm{~h}$ to remove residual solvent and then a further thermal treatment at $150^{\circ} \mathrm{C}$ for $2 \mathrm{~h}$ and then put in a 


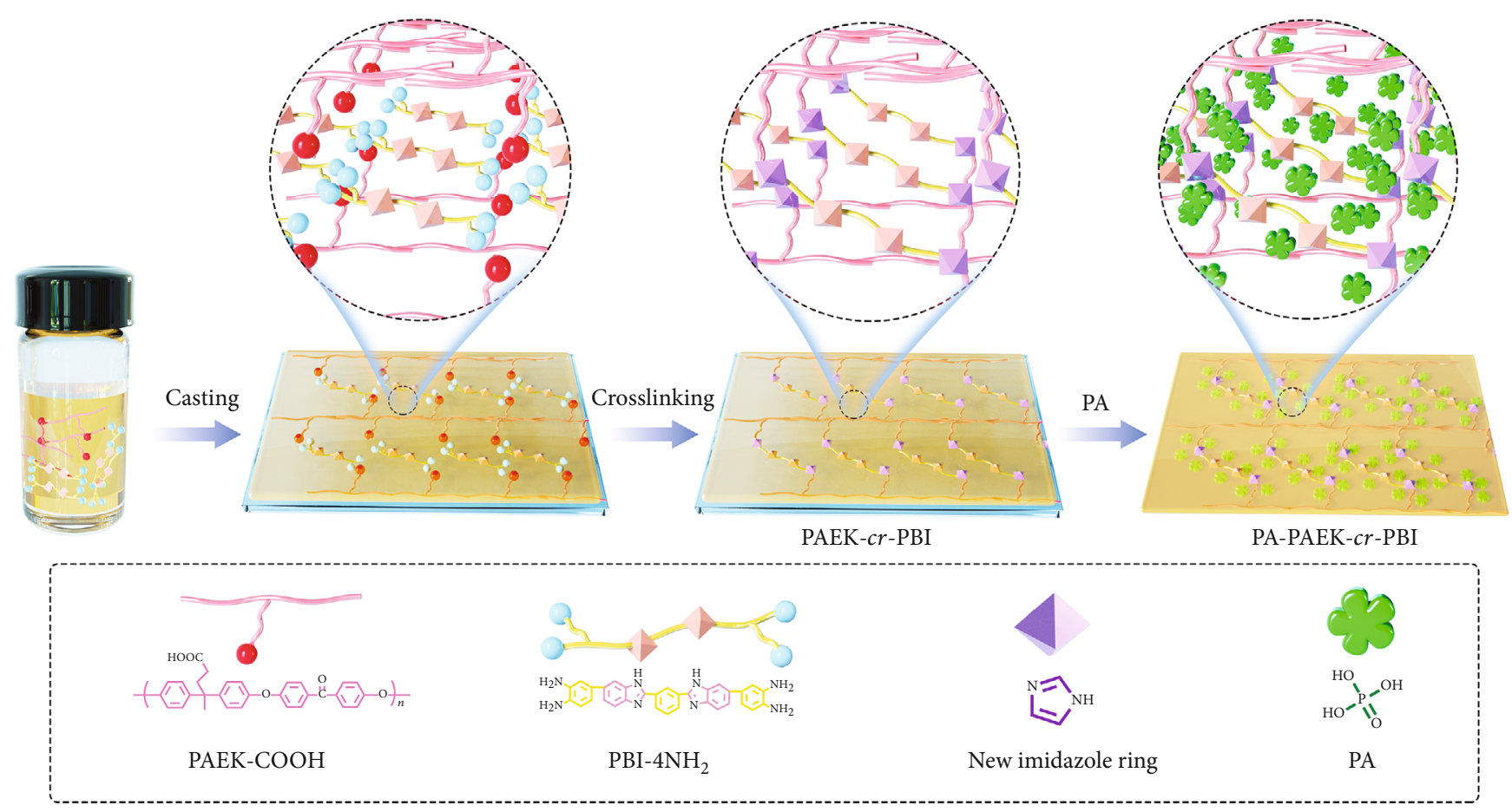

Scheme 2: Schematic diagram of the preparation procedure of the PA-doped 3D network structural PAEK-cr-PBI membrane.

vacuum at $190^{\circ} \mathrm{C}$ for $12 \mathrm{~h}$ for further crosslinking. The obtained membrane was then peeled off, washed thoroughly with deionized water, and dried at $100^{\circ} \mathrm{C}$ for $24 \mathrm{~h}$.

2.3.2. Preparation of the PAEK-cr-PBI@PBI Membrane. Similar to the PAEK-cr-PBI membrane, the composite PAEK-crPBI@PBI membrane was also fabricated by a solution casting method. What needs to be explained here is that the mass ratio between PAEK-cr-PBI and PBI is $4: 1$; the detail of the preparation process is as follows: PAEK-COOH $(300.0 \mathrm{mg})$ and PBI (117.2 mg) were dissolved in $3 \mathrm{~mL}$ 1-methyl-2-pyrrolidinone (NMP) to form a uniformly transparent solution. Then, the PBI- $4 \mathrm{NH}_{2}$ (168.6 mg) was dissolved completely in the 1-2 mL NMP. The rest of the procedure is the same as the preparation process of the PAEK-cr-PBI membrane.

2.3.3. Preparation of the PBI Membrane. The preparation method of the PBI membrane is the most convenient: $0.5 \mathrm{~g}$ PBI was dissolved in $5 \mathrm{~mL} \mathrm{NMP}$ and stirred for $24 \mathrm{~h}$ at room temperature to obtain a homogeneous solution. Then, the polymer solution was cast on a flat glass plate and then dried at $80^{\circ} \mathrm{C}$ for $24 \mathrm{~h}$.

\subsection{Characterizations}

2.4.1. Structural Characterization. ${ }^{1} \mathrm{H}$ NMR spectra of the $\mathrm{PAEK}-\mathrm{COOH}$ and $\mathrm{PBI}-4 \mathrm{NH}_{2}$ were recorded on a Bruker DRX-500 NMR spectrometer with deuterated DMSO (DMSO- $\mathrm{d}_{6}$ ) as the solvent and tetramethylsilane (TMS) as the standard at room temperature. The molecular weight of synthesized PAEK-COOH was measured using a gel permeation chromatography (GPC) system (Waters 515 HPLC Pump, Waters 2414 detector), and the measurement was carried out at $30^{\circ} \mathrm{C}$ with the THF solvent. The surface and cross- section morphologies of the membranes were recorded on scanning electron microscopy (FE-SEM, Quanta 400F).

2.4.2. Solubility Test. The crosslinking degree was characterized by measuring the solubility of the PAEK-cr-PBI and PAEK-cr-PBI@PBI membranes in common solvents. The membranes were immersed in NMP for $12 \mathrm{~h}$ at $90^{\circ} \mathrm{C}$. Then, the residual samples in the NMP solution were collected, dried, and weighed. The weight residue of the membranes was calculated by the following equation:

$$
\text { Gel content }(\%)=\frac{W_{\mathrm{A}}}{W_{\mathrm{B}}} \times 100 \% \text {, }
$$

where $W_{\mathrm{A}}$ is the weight of membranes after the test and $W_{\mathrm{B}}$ is the weight of membranes before the test.

2.4.3. PA Uptake and Swellings. The PBI, PAEK-cr-PBI, and PAEK-cr-PBI@PBI membranes were dried in a vacuum oven at $80^{\circ} \mathrm{C}$ for $12 \mathrm{~h}$. After measuring the weight, length, width, and thickness, they were immersed in $85 \mathrm{wt} \%$ phosphoric acid solution at $120^{\circ} \mathrm{C}$ for $15 \mathrm{~h}$. The membranes were taken out and wiped with tissue wipes. After drying at $100^{\circ} \mathrm{C}$ for $12 \mathrm{~h}$, PA uptake and the length, width, and thickness of each sample were measured immediately. Each type of membranes was tested for three samples, and the average value was reported. The PA uptake ratio of the membrane was calculated by the following equation:

$$
\text { PA uptake }(\%)=\frac{W_{\mathrm{PA}}-W_{\mathrm{D}}}{W_{\mathrm{D}}} \times 100 \% \text {, }
$$



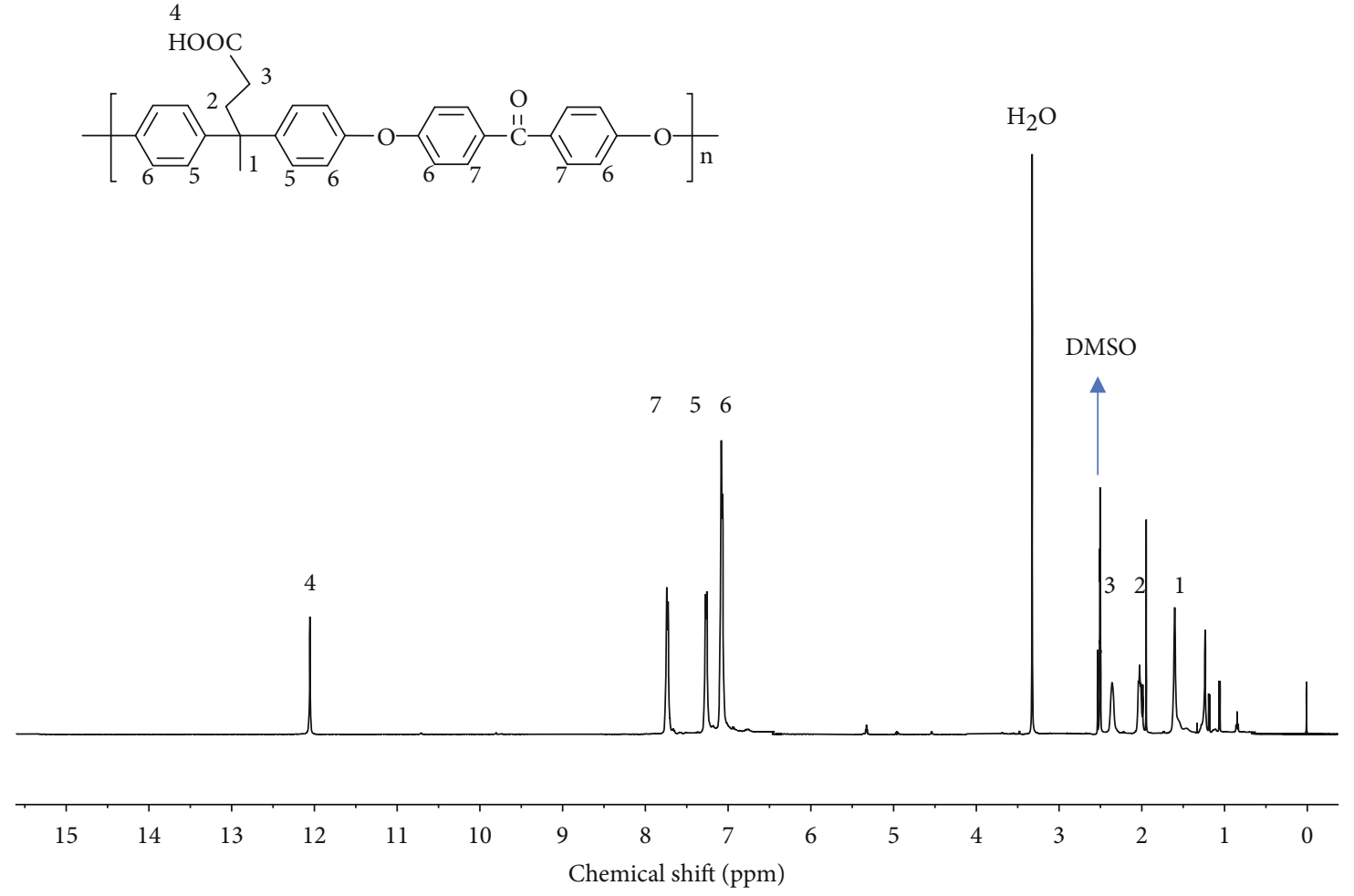

(a)

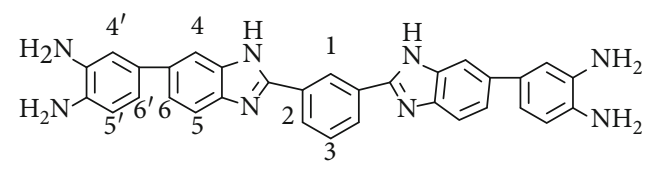

DMSO

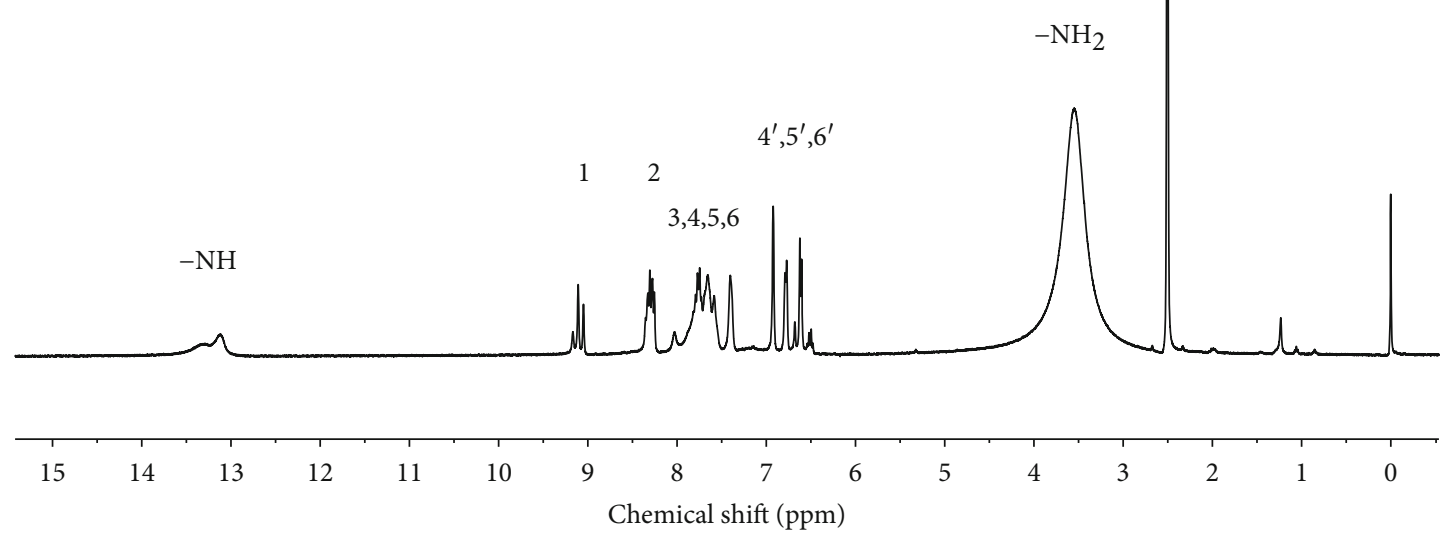

(b)

Figure 2: ${ }^{1} \mathrm{H}$ NMR spectra of (a) PAEK-COOH and (b) PBI-4NH${ }_{2}$. 


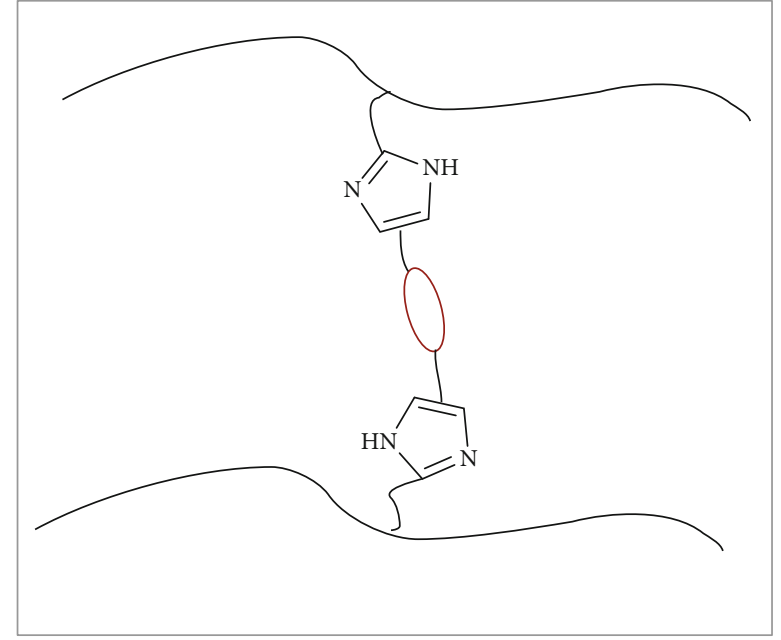

PBI- $4 \mathrm{NH}_{2}$ crosslinking

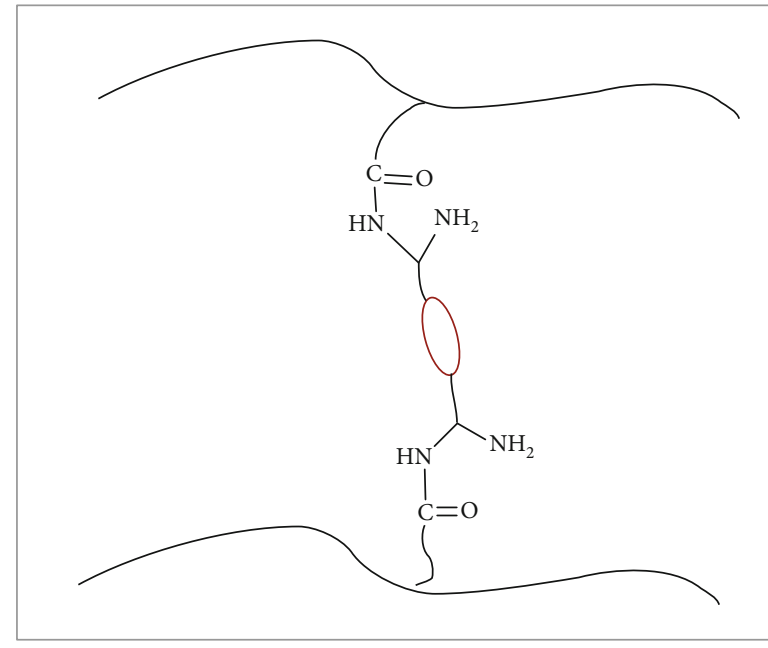

Fake PBI- $4 \mathrm{NH}_{2}$ crosslinking

FIGURE 3: Schematic representation of the possible crosslinking structures of the PAEK-cr-PBI membrane.

where $W_{\mathrm{PA}}$ is the weight of the PA-doped membrane and $W_{\mathrm{D}}$ is the weight of the undoped dry membrane. The dimensional swelling ratio of the membrane was calculated by the following equations:

$$
\begin{gathered}
S_{\text {area }}(\%)=\frac{A_{\mathrm{PA}}-A_{\mathrm{D}}}{A_{\mathrm{D}}} \times 100 \%, \\
S_{\text {volume }}(\%)=\frac{V_{\mathrm{PA}}-V_{\mathrm{D}}}{V_{\mathrm{D}}} \times 100 \%,
\end{gathered}
$$

where $A_{\mathrm{D}}$ and $V_{\mathrm{D}}$ represent the area and volume of the dry membrane, respectively, and $A_{\mathrm{PA}}$ and $V_{\mathrm{PA}}$ represent the area and volume of the wet membrane, respectively, after being immersed in $85 \mathrm{wt} \%$ phosphoric acid solution at $120^{\circ} \mathrm{C}$.

2.4.4. Thermal Stability. The thermogravimetric (TGA) curves of membranes were obtained by Pyris 1 TGA (PerkinElmer) under the nitrogen atmosphere. All the samples were preheated at $100^{\circ} \mathrm{C}$ for $2 \mathrm{~h}$ to eliminate the absorbed water and organic solvents before testing. Then, the samples were tested from 50 to $800^{\circ} \mathrm{C}$ with a heating rate of $10^{\circ} \mathrm{C} \mathrm{min}^{-1}$.

2.4.5. Oxidative Stability. To test oxidative stability, the undoped membrane samples were immersed into Fenton's reagent $\left(3 \% \mathrm{H}_{2} \mathrm{O}_{2}\right.$ solution containing $\left.4 \mathrm{ppm} \mathrm{Fe}{ }^{2+}\right)$ at $80^{\circ} \mathrm{C}$ for $40 \mathrm{~h}$; then, the samples were removed from the solution and dried in a vacuum oven at $120^{\circ} \mathrm{C}$ for $12 \mathrm{~h}$. Each type of membranes was tested for 3 samples, and the average value was reported. The residual weight of the samples represented the oxidative stability $[18,41]$.

2.4.6. Proton Conductivity. The proton conductivities of PBI, PAEK-cr-PBI, and PAEK-cr-PBI@PBI membranes were measured by electrochemical impedance spectroscopy (EIS) using a PGSTAT204 electrochemical workstation (AUT50992, AUTOLAB). The membrane sample was immersed in $85 \mathrm{wt} \%$ PA solution for $12 \mathrm{~h}$ at room temperature before testing. The impedance measurement was performed under anhy-
1
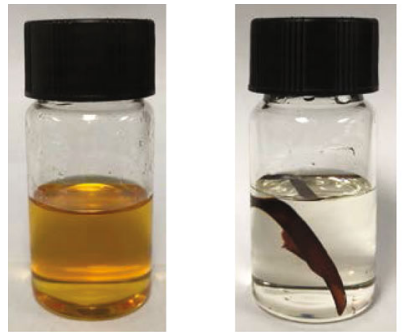

(a)

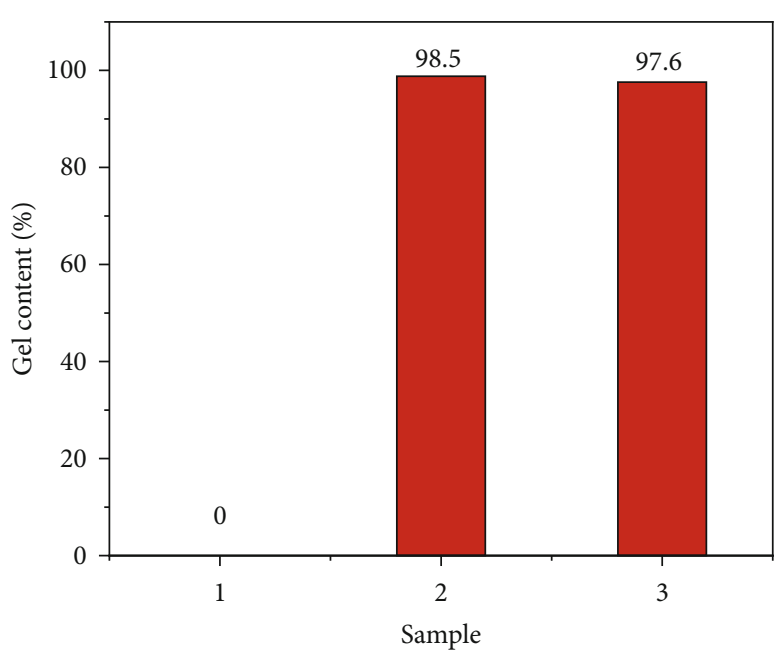

(b)

Figure 4: (a) Photographs and (b) gel content of membranes after the solubility test in NMP at $90^{\circ} \mathrm{C}$ for $12 \mathrm{~h}$. (1) PBI, (2) PAEK-crPBI, and (3) PAEK-cr-PBI@PBI. 


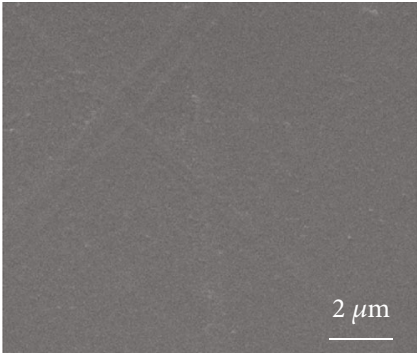

(a)

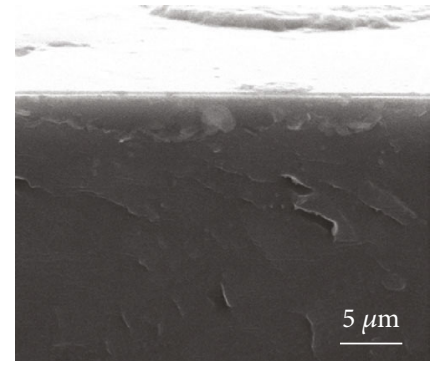

(d)

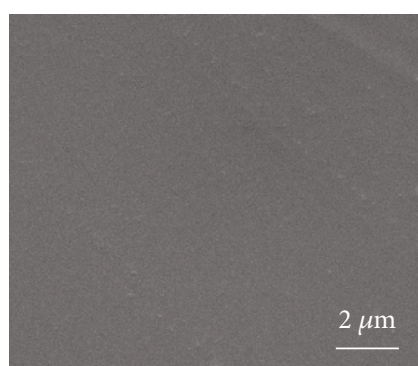

(b)

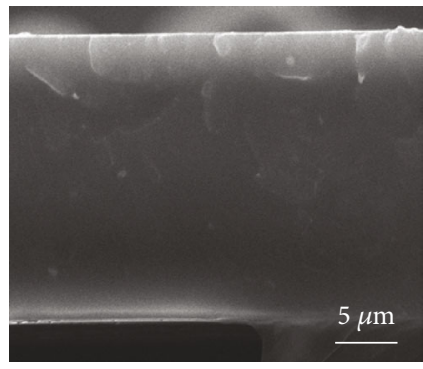

(e)

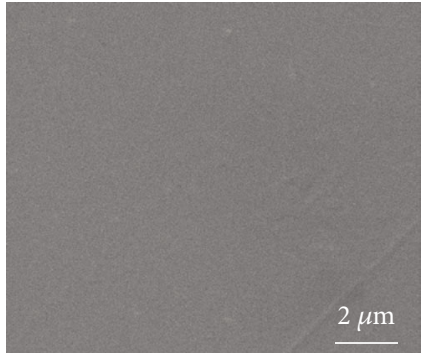

(c)

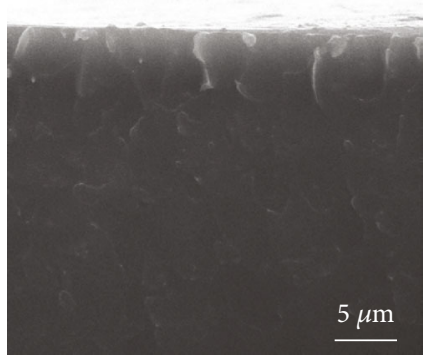

(f)

FIGURE 5: SEM micrographs of the surface (up) and cross-section (down) of PA-undoped membranes: (a, d) PBI, (b, e) PAEK-cr-PBI, and (c, f) PAEK-cr-PBI@PBI.

drous conditions from $120^{\circ} \mathrm{C}$ to $170^{\circ} \mathrm{C}$ in the frequency range of $0.1 \mathrm{~Hz}$ to $100 \mathrm{kHz}$. The conductivity is calculated by the following equation:

$$
\sigma=\frac{L}{R \times W \times T}
$$

where $L(\mathrm{~cm})$ is the distance between two electrodes, $R(\Omega)$ is the membrane resistance obtained by a Nyquist plot, and $W$ $(\mathrm{cm})$ and $T(\mathrm{~cm})$ are the width and thickness of the membrane, respectively.

2.4.7. Mechanical Properties. The mechanical properties of PA-doped membranes were evaluated on a tensile tester (New SANS, Shenzhen, China) with a stretching speed of $10 \mathrm{~mm} / \mathrm{min}$ under an ambient atmosphere. The size of all the samples is $6 \mathrm{~mm} \times 40 \mathrm{~mm}$. Before testing, the PA-doped membranes were dried in a vacuum oven at $100^{\circ} \mathrm{C}$ for $24 \mathrm{~h}$ to remove any absorbed water or organic solvents. Each type of membranes was tested for 4 samples, and the average value was reported.

\section{Results and Discussion}

3.1. Chemical Structure Identification. From the GPC analysis, the number and weight average molecular weights of PAEK-COOH were 40,000 and 92,000 $\mathrm{g} \mathrm{mol}^{-1}$, respectively. This result suggests that the polymer possesses a high enough molecular weight to form a membrane.

The synthesized PAEK-COOH and PBI- $4 \mathrm{NH}_{2}$ were analyzed using ${ }^{1} \mathrm{H}$ NMR (500 MHz, DMSO-d6), and the presence of carboxyl and amino groups was confirmed as shown in Figure 1. As it can be seen in Figure 2(a), the protons in the benzene ring of the polymer main chain show chemical shifts at 7.06, 7.27, and $7.73 \mathrm{ppm}$; the NMR peak at $12.05 \mathrm{ppm}$ comes from the proton in the carboxyl group of PAEK$\mathrm{COOH}$. In Figure 2(b), the broad peak at $13.10 \mathrm{ppm}$ is attributed to the $-\mathrm{NH}$ proton of the benzimidazole groups. Peaks of 9.05-9.16 ppm are assigned to protons (H1) near the two benzimidazole groups. Peaks in the range of 6.93-6.50 ppm are ascribed to aromatic protons of benzene rings $\left(\mathrm{H} 3^{\prime}, \mathrm{H} 4^{\prime}\right.$, and $\mathrm{H}^{\prime}$ ) at both ends. Peaks in the range of 8.28-7.41 are attributed to the remaining aromatic protons (H2-6). The broad peak at $3.55 \mathrm{ppm}$ is attributed to protons of the terminal amino group. The results of peak distribution indicate that the desired PBI- $4 \mathrm{NH}_{2}$ was prepared successfully.

The schematic representation of the possible crosslinking structures of the crosslinked membrane is shown in Figure 3. Because of the insolubility of the crosslinked membrane (PAEK-cr-PBI), it is difficult to confirm the imidazolization between PAEK-COOH and $\mathrm{PBI}-4 \mathrm{NH}_{2}$ by the conventional analysis.

The solubility test was carried out to ascertain the crosslinking degree of PAEK-cr-PBI and PAEK-cr-PBI@PBI successfully. It is easy to know that if a complete dissolution of the membrane occurs, there is no crosslinking in the membrane. On the other hand, if the membrane has a residual sample after a period of immersing, the membrane is approved to be crosslinked. As shown in Figure 4, PAEK-cr-PBI and PAEK-cr-PBI@PBI membrane samples maintained the structural integrity after immersing in NMP at $90^{\circ} \mathrm{C}$ for $12 \mathrm{~h}$. The weight of the PAEK-cr-PBI and PAEK-cr-PBI@PBI sample was over $97 \%$ after treatment. These results confirm that the crosslinking occurred between PAEK-COOH and PBI- $4 \mathrm{NH}_{2}$. In addition, there was no significant dissolution of $\mathrm{PBI}$ in the PAEK-cr-PBI@PBI membrane, which may be owing to the network structure of PAEK-cr-PBI suppressing PBI molecular 


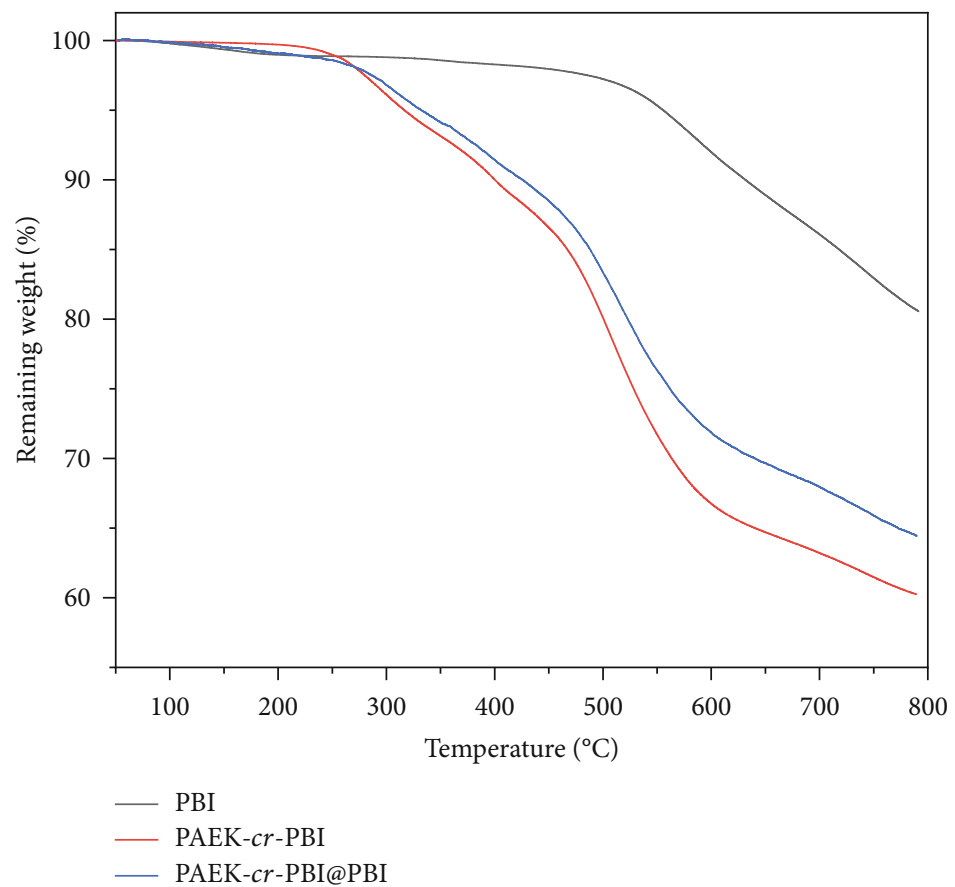

(a)

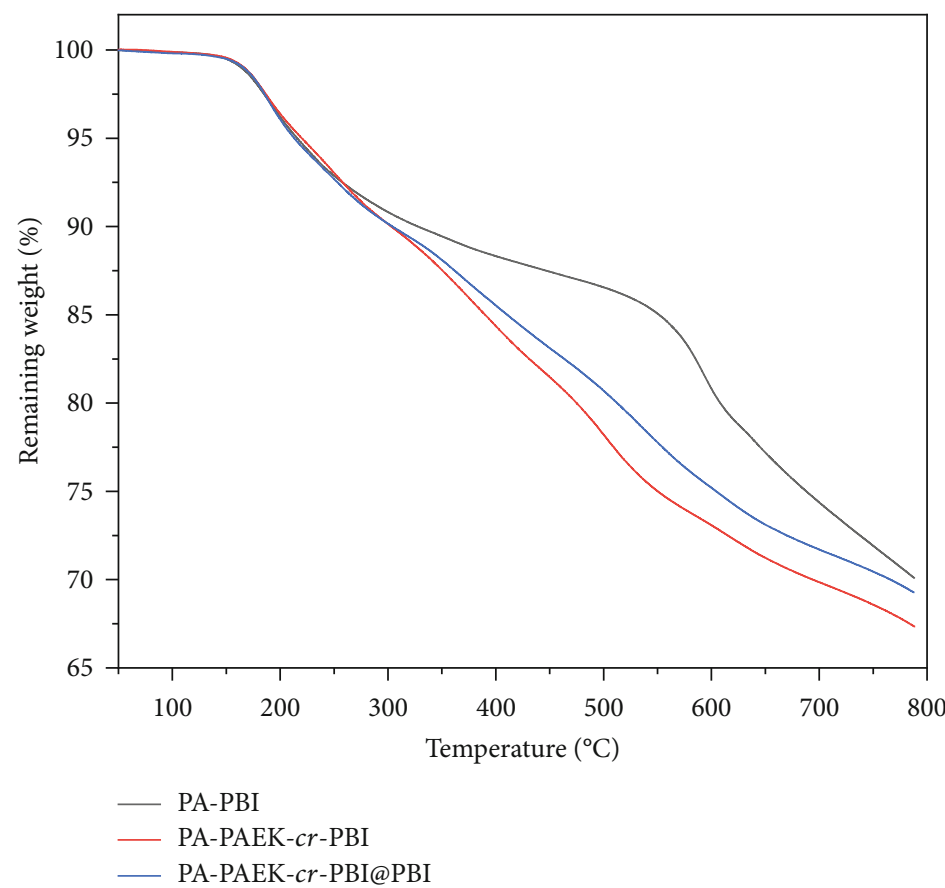

(b)

Figure 6: TGA curves of (a) PA-undoped and (b) PA-doped membranes under the $\mathrm{N}_{2}$ atmosphere.

chain movement. On the contrary, the noncrosslinked membranes (PBI) completely dissolved in NMP in $2 \mathrm{~h}$.

3.2. Morphology Analysis. The surface and cross-section morphologies of the prepared membranes were studied using SEM micrography. In Figure 5, it is observed that PAEK-crPBI and PAEK-cr-PBI@PBI membranes show a completely homogenous and compact structure without pores as well as the PBI membrane, which is essential for separating the fuel and oxidant during fuel cell operation and benefits the fuel cell performance.

3.3. Thermal Stability. Thermal stability of polymer electrolytes is one of the most critical features for long-term durability of fuel cells, especially in high-temperature operation. The thermal stability of PA-undoped and PA-doped membranes was studied by TGA under the nitrogen atmosphere. As shown in Figure 6(a), two-step degradation can be observed 


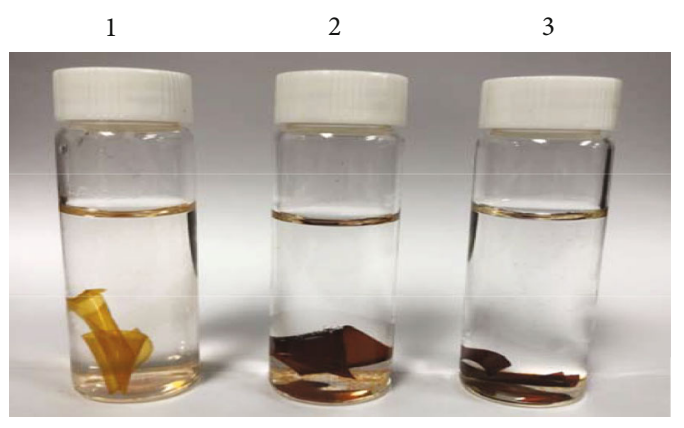

(a)

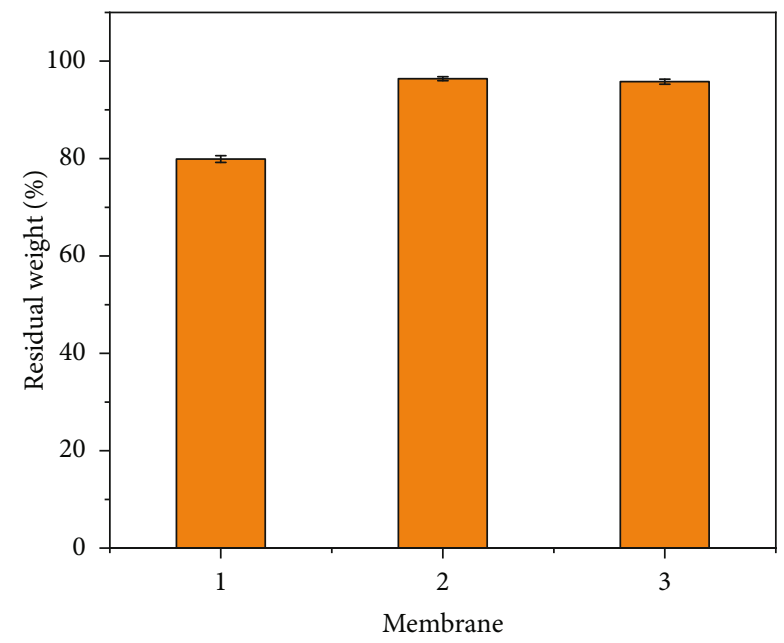

(b)

FIgURE 7: (a) Photographs and (b) residual weight of the membranes after the Fenton test: (1) PBI, (2) PAEK-cr-PBI, and (3) PAEK-cr-PBI@PBI.

in both undoped PAEK-cr-PBI and PAEK-cr-PBI@PBI membrane samples. The first weight loss beginning at around $250^{\circ} \mathrm{C}$ was attributed to the degradation of imidazole groups and carboxyl groups on the side chains, which suggested that the amino and carboxyl groups do not react completely. The second step observed at about $470^{\circ} \mathrm{C}$ was due to the degradation of the polymer main chain, including poly (aryl ether ketone) (PAEK) and poly $\left(4,4^{\prime}\right.$-(diphenyl ether)-5, $5^{\prime}$-bibenzimidazole) (PBI). On the other hand, the undoped PBI membrane decomposed only in one step at around $500^{\circ} \mathrm{C}$. After doping with PA, as shown in Figure 6(b), for all the membranes, weight loss appeared earlier at about $160^{\circ} \mathrm{C}$ because of the dehydration of phosphoric acid. Nonetheless, the degradation of polymer membranes itself was observed in the temperature range similar to that of PA-undoped polymer membranes. The TGA results show that both PAEK-crPBI and PAEK-cr-PBI@PBI membranes exhibit excellent thermal stabilities and can be used for HT-PEMFCs.

3.4. Oxidative Stability. To estimate the long-term stability of PEMs, the oxidative stability of the membranes was measured by the Fenton test. During the fuel cell operation, the incom-
TABLE 1: PA doping behavior of the membranes.

\begin{tabular}{lccc}
\hline Membrane & PA uptake (\%) & $S_{\text {area }}(\%)$ & $S_{\text {volume }}(\%)$ \\
\hline PBI & $231 \pm 8$ & $50 \pm 2$ & $136 \pm 7$ \\
PAEK-cr-PBI & $193 \pm 5$ & $37 \pm 2$ & $79 \pm 4$ \\
PAEK-cr-PBI@PBI & $224 \pm 6$ & $43 \pm 2$ & $124 \pm 5$ \\
\hline
\end{tabular}

1
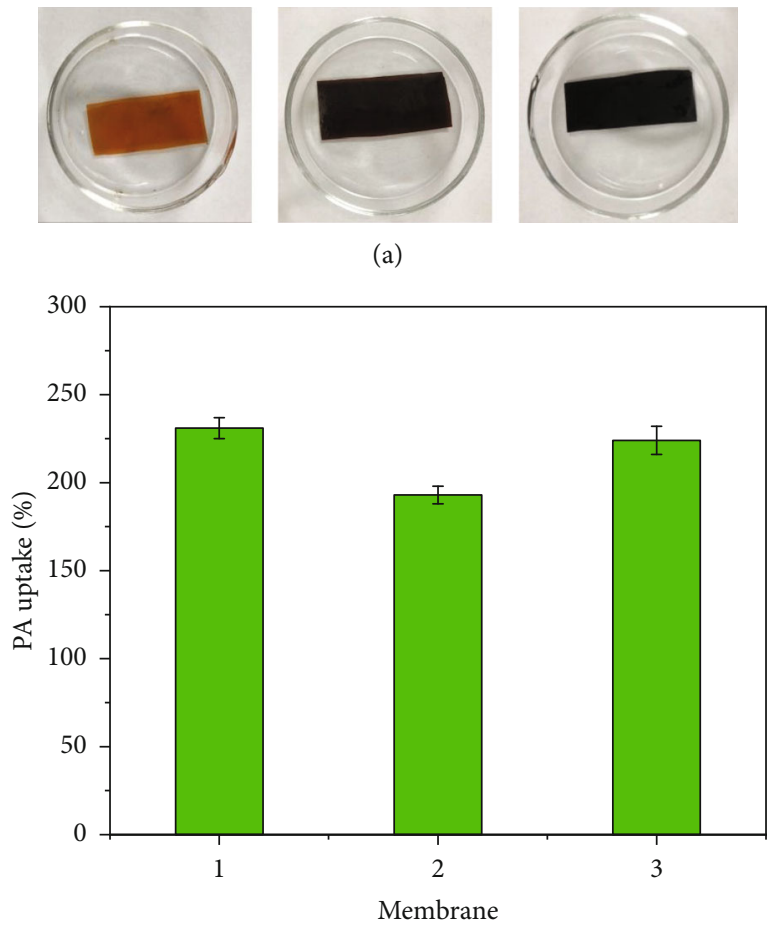

(b)
Figure 8: (a) Photographs of the PA-doped membrane and (b) PA uptake of the membranes: (1) PBI, (2) PAEK-cr-PBI, and (3) PAEKcr-PBI@PBI.

plete reduction of oxygen produces $\mathrm{HO}^{\bullet}$ and $\mathrm{HO}_{2}{ }^{\bullet}$ radicals. Subsequently, these lively radicals attack the skeleton of the polymer membrane, which causes membrane degradation. The degradation of the membranes was investigated by determining the weight loss. As shown in Figure 7, the PAEK-crPBI and PAEK-cr-PBI@PBI membranes show superior oxidative stabilities as compared to the PBI membrane. It is because the densely crosslinked structure reduces the possibility of radical species to attack the polymer chain. After $40 \mathrm{~h}$ of the Fenton test, only $79.9 \%$ of the initial weight of the linear PBI membrane remained. However, the residual weight values of PAEK-cr-PBI and PAEK-cr-PBI are both more than 95\%. The results indicated that the polymer PAEK-cr-PBI exhibited excellent oxidative stability.

3.5. PA Uptakes and Swellings. The proton transport of HTPEMs depends on the dissociation of phosphoric acid, so the content of free phosphoric acid has a direct impact on proton conductivity of HT-PEM materials. The PA-doped membranes were obtained by immersing the dried membranes into $85 \mathrm{wt} \%$ phosphoric acid solution at $120^{\circ} \mathrm{C}$ for $15 \mathrm{~h}$, and the $\mathrm{PA}$ 


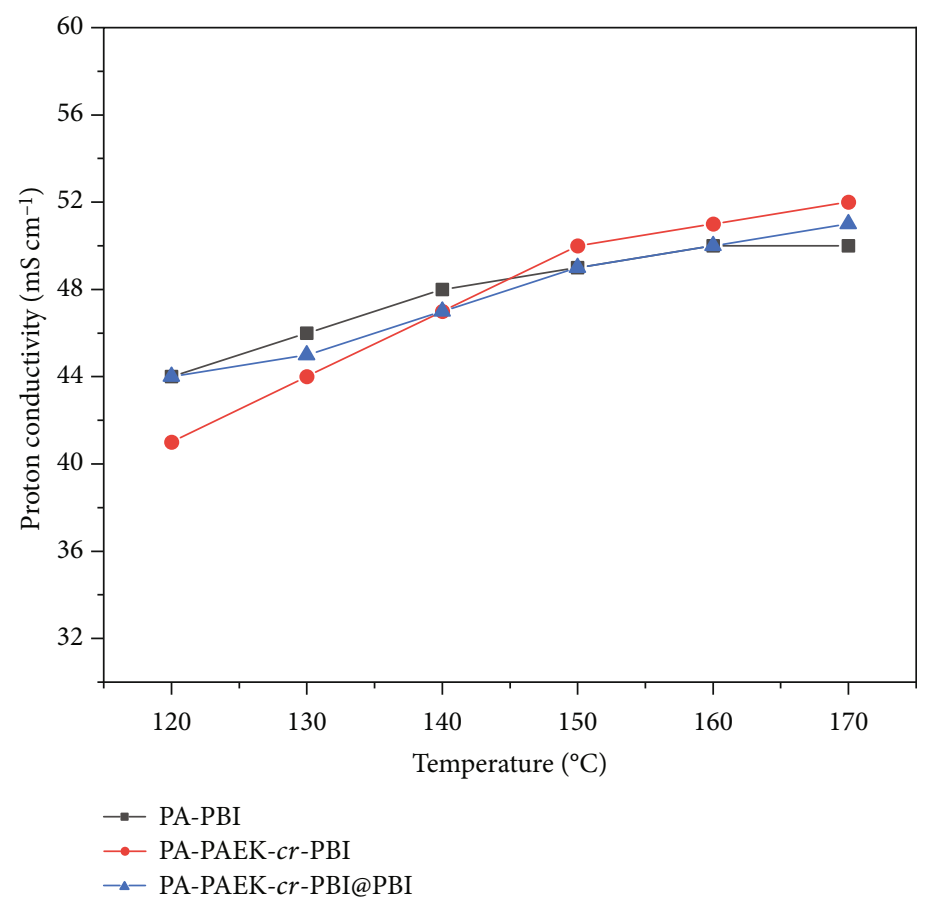

FIGURE 9: Proton conductivity of PA-doped membranes.

uptake and swelling ratio of the membrane are summarized in Table 1. To make it easier to follow, the photographs of the PA-doped membranes and histogram of PA uptake of the PBI, PAEK-cr-PBI, and PAEK-cr-PBI@PBI membranes are shown in Figure 8.

As it can be seen in Figure 8, the highest PA uptake was obtained by the PBI membrane. However, the PA uptakes of the membranes synthesized in this study are not disappointing. As it can be seen in Table 1, the PAEK-cr-PBI and PAEK-cr-PBI@PBI membranes have a PA uptake of 193\% and 224\%, respectively. Obviously, the PAEK-cr-PBI@PBI membrane, which is the membrane PAEK-cr-PBI blended with some PBI, did absorb more phosphoric acid than the PAEK-cr-PBI membrane without PBI.

In respect to the swelling of the membrane caused by doping PA molecules, the PAEK-cr-PBI membrane showed a volume swelling of below $80 \%$ and an area swelling of below $40 \%$. The low swelling of the PA-doped PAEK-cr-PBI membrane probably benefited from its crosslinked structure and the skeleton stability of the poly (aryl ether ketone) matrix. However, the swelling of the membrane with PBI (PAEKcr-PBI@PBI) was higher than that of the pristine PAEK-crPBI membrane. That may be due to the enhancement of PA uptake of the membrane or the plasticizing effect of phosphoric acid on the PAEK-cr-PBI framework.

3.6. Proton Conductivities. The proton conductivity measurement was carried out from 120 to $170^{\circ} \mathrm{C}$ in anhydrous condition. In order to evaluate the proton conductivity of crosslinked PAEK-cr-PBI and PAEK-cr-PBI@PBI membranes, the well-documented PBI membrane was selected as the comparison. In Figure 9, the proton conductivities of all the membranes increase with the increase in the testing temperature as we expected. It is interesting to see that these three kinds of membranes have almost the same proton conduction ability, which demonstrates that the proton conductivity of the PAEK-cr-PBI and PAEK-cr-PBI@PBI membranes is comparable to that of the traditional PBI membrane. However, there is a change observed in the slope above $150^{\circ} \mathrm{C}$ for the proton conductivity curves of all membranes, which may be due to the transformation of a proton conducting mechanism, because the condensed phosphoric acids such as the dimer (pyrophosphoric acid $\left(\mathrm{H}_{4} \mathrm{P}_{2} \mathrm{O}_{7}\right)$ ), trimer (meta- or tripolyphosphoric acid $\left(\mathrm{H}_{5} \mathrm{P}_{3} \mathrm{O}_{10}\right)$ ), and larger fused structures were formed when the temperature is over $150^{\circ} \mathrm{C}$ [1]. Obviously, when the temperature is over $150^{\circ} \mathrm{C}$, the PAEK-cr-PBI membrane with the lowest PA uptake exhibits the highest proton conductivity, which illustrates that the 3D network structure of the membrane is conducive to proton conduction.

3.7. Mechanical Properties. It is well known that the excellent mechanical properties of HT-PEMs are essential for practical application. The typical stress-strain curves of the membranes at room temperature are shown in Figure 10, and the mechanical properties are displayed in Table 2. As shown in Figure 10, the PA-doped PAEK-cr-PBI membrane exhibits the best tensile strength of $17 \mathrm{MPa}$ among the three kinds of membranes as expected. In the meanwhile, the PA-doped PAEK-cr-PBI@PBI membrane also showed fairly excellent mechanical strength of over $10 \mathrm{MPa}$. However, the tensile strength of the PA-doped PBI membrane is only about 3.5 MPa. These results show that the PA-doped 3D network structural PAEK-cr-PBI membrane has outstanding mechanical properties; moreover, it can be used as a support material to improve the mechanical properties of PA-doped PBI membrane without reducing the proton conductivity. 


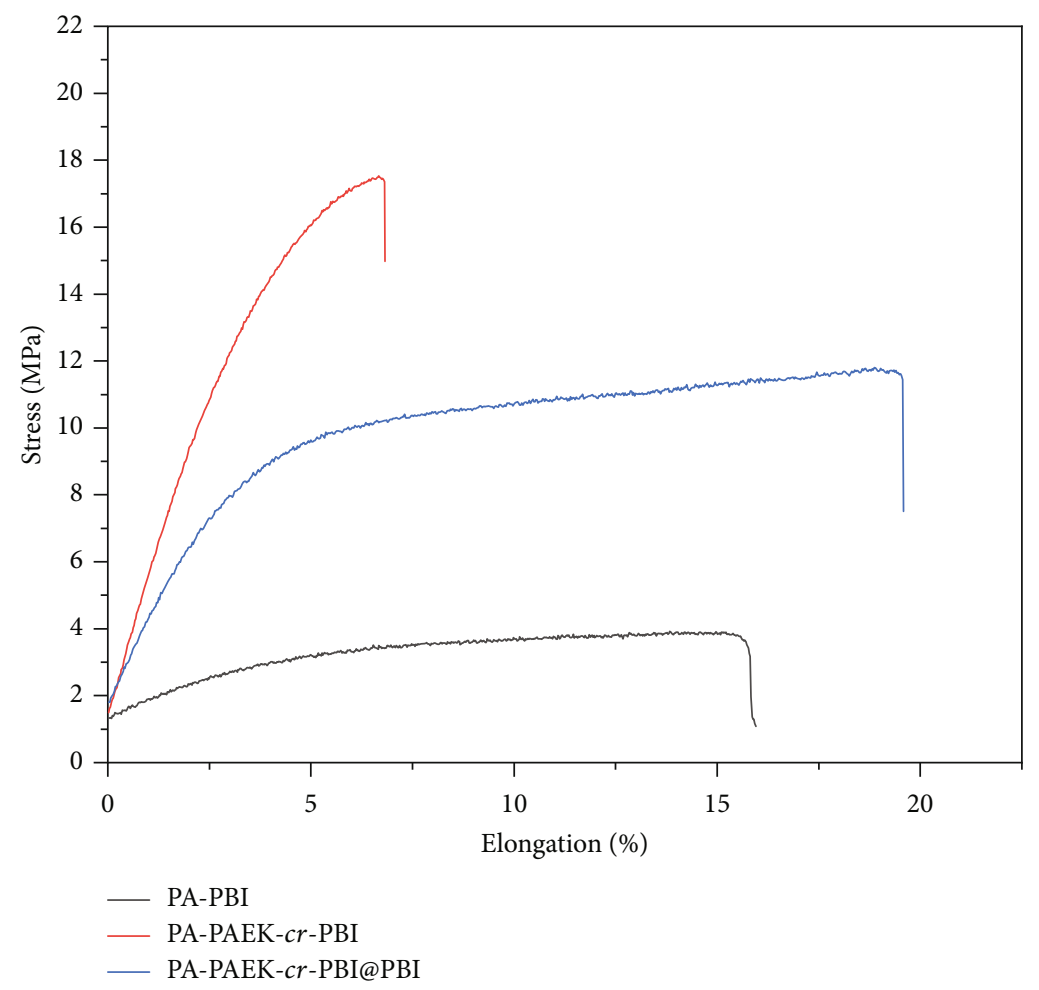

Figure 10: Mechanical properties of PA-doped membranes at room temperature.

TABLE 2: Summary of proton conductivities and mechanical properties of PA-doped membranes.

\begin{tabular}{lcccc}
\hline Membrane & PA uptake $(\%)$ & Proton conductivity $\left(\mathrm{mS} \mathrm{cm}^{-1}\right)^{\mathrm{a}}$ & ${\text { Tensile strength }(\mathrm{MPa})^{\mathrm{b}}}^{\text {Elongation }(\%)^{\mathrm{b}}}$ \\
\hline PBI & $231 \pm 8$ & 50 & $3.5 \pm 0.4$ & $15.8 \pm 2.4$ \\
PAEK-cr-PBI & $193 \pm 5$ & 52 & $17.0 \pm 0.4$ & $9.7 \pm 1.1$ \\
PAEK-cr-PBI@PBI & $224 \pm 6$ & 51 & $11.4 \pm 0.3$ & $19.7 \pm 3.2$ \\
\hline
\end{tabular}

${ }^{\mathrm{a}}$ Measured at $170^{\circ} \mathrm{C}$ and under anhydrous condition. ${ }^{\mathrm{b}}$ Measured at room temperature.

\section{Conclusions}

In this work, a 3D network structural PAEK-cr-PBI membrane was prepared and investigated as HT-PEMs for HTPEMFCs. The 3D network structural membrane PAEK-crPBI and the composite membrane PAEK-cr-PBI@PBI both showed excellent thermal stability which is suitable for operation in the high-temperature range of $120 \sim 180^{\circ} \mathrm{C}$. Moreover, the PAEK-cr-PBI and PAEK-cr-PBI@PBI membranes exhibit excellent proton conductivities of about $50 \mathrm{mS} \mathrm{cm}^{-1}$ at $170^{\circ} \mathrm{C}$, which are comparable to those of the traditional PBI membrane. As an encouraging result, the PA-doped PAEK-cr-PBI membrane showed superior mechanical properties of $17 \mathrm{MPa}$ than the PA-doped linear PBI membrane, which is only $3.5 \mathrm{MPa}$. These results show that the assynthesized PAEK-cr-PBI gives a highly practical promise for its application in HT-PEMFCs.

\section{Data Availability}

All of the data used to support the findings of this study are included within the article.

\section{Conflicts of Interest}

There is no conflict of interest.

\section{Acknowledgments}

This work was supported by the National Key Research and Development Program (2018YFA0702002), the Link Project of the National Natural Science Foundation of China and Guangdong Province (Grant No. U1601211), the National Key Research and Development Program (Japan-China Joint Research Program) (2017YFE9127900), the National Natural Science Foundation of China (51573215, 21506260, 21706294, and 21376276), the Natural Science Foundation of Guangdong Province (2016A030313354), Guangdong Science and Technology Department (Grant Nos. 2016A050503001, 2016B010114004, and 2017B090901003), the Guangzhou Science and Technology Plan Project (Grant Nos. 201804020025 and 201707010424), and the Fundamental Research Funds for the Central Universities (Grant Nos. 17lgjc37, 18lgpy32, and 19lgpy07). 


\section{References}

[1] W. Ma, C. Zhao, J. Yang et al., "Cross-linked aromatic cationic polymer electrolytes with enhanced stability for high temperature fuel cell applications," Energy \& Environmental Science, vol. 5, no. 6, pp. 7617-7625, 2012.

[2] J. Yang, Q. Li, L. N. Cleemann et al., "Crosslinked hexafluoropropylidene polybenzimidazole membranes with chloromethyl polysulfone for fuel cell applications," Advanced Energy Materials, vol. 3, no. 5, pp. 622-630, 2013.

[3] S. Wang, C. Zhao, W. Ma et al., "Silane-cross-linked polybenzimidazole with improved conductivity for high temperature proton exchange membrane fuel cells," Journal of Materials Chemistry A, vol. 1, no. 3, pp. 621-629, 2013.

[4] Z. Guo, X. Xu, Y. Xiang, S. Lu, and S. P. Jiang, "New anhydrous proton exchange membranes for high-temperature fuel cells based on PVDF-PVP blended polymers," Journal of Materials Chemistry A, vol. 3, no. 1, pp. 148-155, 2015.

[5] K. J. Kallitsis, R. Nannou, A. K. Andreopoulou et al., "Crosslinked wholly aromatic polyether membranes based on quinoline derivatives and their application in high temperature polymer electrolyte membrane fuel cells," Journal of Power Sources, vol. 379, pp. 144-154, 2018.

[6] S. S. Araya, F. Zhou, V. Liso et al., "A comprehensive review of PBI-based high temperature PEM fuel cells," International Journal of Hydrogen Energy, vol. 41, no. 46, pp. 2131021344, 2016.

[7] A. Chandan, M. Hattenberger, A. el-kharouf et al., "High temperature (HT) polymer electrolyte membrane fuel cells (PEMFC) - A review," Journal of Power Sources, vol. 231, pp. 264-278, 2013.

[8] F. Liu, S. Wang, H. Chen et al., "Cross-linkable polymeric ionic liquid improve phosphoric acid retention and long-term conductivity stability in polybenzimidazole based PEMs," ACS Sustainable Chemistry \& Engineering, vol. 6, no. 12, pp. 16352-16362, 2018.

[9] J. Fang, X. Lin, D. Cai, N. He, and J. Zhao, "Preparation and characterization of novel pyridine-containing polybenzimidazole membrane for high temperature proton exchange membrane fuel cells," Journal of Membrane Science, vol. 502, pp. 29-36, 2016.

[10] J. A. Asensio, E. M. Sánchez, and P. Gómez-Romero, "Protonconducting membranes based on benzimidazole polymers for high-temperature PEM fuel cells. A chemical quest," Chemical Society Reviews, vol. 39, no. 8, pp. 3210-3239, 2010.

[11] F. J. Pinar, P. Cañizares, M. A. Rodrigo, D. Úbeda, and J. Lobato, "Long-term testing of a high-temperature proton exchange membrane fuel cell short stack operated with improved polybenzimidazole-based composite membranes," Journal of Power Sources, vol. 274, pp. 177-185, 2015.

[12] S. Gao, H. Xu, T. Luo et al., "Novel proton conducting membranes based on cross-linked sulfonated polyphosphazenes and poly(ether ether ketone)," Journal of Membrane Science, vol. 536, pp. 1-10, 2017.

[13] L. Vilčiauskas, M. E. Tuckerman, G. Bester, S. J. Paddison, and K. D. Kreuer, "The mechanism of proton conduction in phosphoric acid," Nature Chemistry, vol. 4, no. 6, pp. 461-466, 2012.

[14] J. Kerres and V. Atanasov, "Cross-linked PBI-based hightemperature membranes: stability, conductivity and fuel cell performance," International Journal of Hydrogen Energy, vol. 40, no. 42, pp. 14723-14735, 2015.
[15] Y. Cai, Z. Yue, X. Teng, and S. Xu, "Phosphoric acid doped crosslinked polybenzimidazole/modified graphene oxide composite membranes for high temperature proton exchange membrane applications," Journal of The Electrochemical Society, vol. 165, no. 11, pp. F914-F920, 2018.

[16] Y. Cai, Z. Yue, X. Teng, and S. Xu, "Radiation grafting graphene oxide reinforced polybenzimidazole membrane with a sandwich structure for high temperature proton exchange membrane fuel cells in anhydrous atmosphere," European Polymer Journal, vol. 103, pp. 207-213, 2018.

[17] Y. Cai, Z. Yue, Q. Jiang, and S. Xu, "Modified silicon carbide whisker reinforced polybenzimidazole used for high temperature proton exchange membrane," Journal of Energy Chemistry, vol. 27, no. 3, pp. 820-825, 2018.

[18] J. Jiang, X. Zhu, H. Qian et al., "Cross-linked sulfonated poly (ether ether ketone) electrolytes bearing pendent imidazole groups for high temperature proton exchange membrane fuel cells," Sustainable Energy \& Fuels, vol. 3, no. 9, pp. 24262434, 2019.

[19] D. Joseph, N. N. Krishnan, D. Henkensmeier et al., “Thermal crosslinking of $\mathrm{PBI} /$ sulfonated polysulfone based blend membranes," Journal of Materials Chemistry A, vol. 5, no. 1, pp. 409-417, 2017.

[20] C.-H. Shen and S. L.-C. Hsu, "Synthesis of novel cross-linked polybenzimidazole membranes for high temperature proton exchange membrane fuel cells," Journal of Membrane Science, vol. 443, pp. 138-143, 2013.

[21] Z. Yue, Y.-B. Cai, and S. Xu, "Phosphoric acid-doped organicinorganic cross-linked sulfonated poly(imide- benzimidazole) for high temperature proton exchange membrane fuel cells," International Journal of Hydrogen Energy, vol. 41, no. 24, pp. 10421-10429, 2016.

[22] Z. Yue, Y.-B. Cai, and S. Xu, "Phosphoric acid-doped crosslinked sulfonated poly(imide-benzimidazole) for proton exchange membrane fuel cell applications," Journal of Membrane Science, vol. 501, pp. 220-227, 2016.

[23] Z. Yue, Y.-B. Cai, and S. Xu, "Proton conducting sulfonated poly (imide-benzimidazole) with tunable density of covalent/ionic cross-linking for fuel cell membranes," Journal of Power Sources, vol. 286, pp. 571-579, 2015.

[24] J. Yang, Y. Xu, P. Liu, L. Gao, Q. Che, and R. He, "Epoxides cross-linked hexafluoropropylidene polybenzimidazole membranes for application as high temperature proton exchange membranes," Electrochimica Acta, vol. 160, pp. 281-287, 2015.

[25] H.-L. Lin, Y.-C. Chou, T. L. Yu, and S. W. Lai, "Poly(benzimidazole)-epoxide crosslink membranes for high temperature proton exchange membrane fuel cells," International Journal of Hydrogen Energy, vol. 37, no. 1, pp. 383-392, 2012.

[26] C.-H. Shen, L. C. Jheng, S. L. C. Hsu, and J. Tse-Wei Wang, "Phosphoric acid-doped cross-linked porous polybenzimidazole membranes for proton exchange membrane fuel cells," Journal of Materials Chemistry, vol. 21, no. 39, pp. 1566015665, 2011.

[27] Q. Li, C. Pan, J. O. Jensen, P. Noyé, and N. J. Bjerrum, "Crosslinked polybenzimidazole membranes for fuel cells,", Chemistry of Materials, vol. 19, no. 3, pp. 350-352, 2007.

[28] M. Han, G. Zhang, Z. Liu et al., "Cross-linked polybenzimidazole with enhanced stability for high temperature proton exchange membrane fuel cells," Journal of Materials Chemistry, vol. 21, no. 7, pp. 2187-2193, 2011. 
[29] J. Yang, D. Aili, Q. Li et al., "Covalently cross-linked sulfone polybenzimidazole membranes with poly (vinylbenzyl chloride) for fuel cell applications," Chem Sus Chem, vol. 6, no. 2, pp. 275-282, 2013.

[30] S. Wang, C. Zhao, W. Ma et al., "Macromolecular cross-linked polybenzimidazole based on bromomethylated poly (aryl ether ketone) with enhanced stability for high temperature fuel cell applications," Journal of Power Sources, vol. 243, pp. 102$109,2013$.

[31] L. Wang, Z. Liu, Y. Liu, and L. Wang, "Crosslinked polybenzimidazole containing branching structure with no sacrifice of effective N-H sites: towards high-performance hightemperature proton exchange membranes for fuel cells," Journal of Membrane Science, vol. 583, pp. 110-117, 2019.

[32] C. M. Tuan and D. Kim, "Anion-exchange membranes based on poly(arylene ether ketone) with pendant quaternary ammonium groups for alkaline fuel cell application," Journal of Membrane Science, vol. 511, pp. 143-150, 2016.

[33] D. D. Tham and D. Kim, "C2 and N3 substituted imidazolium functionalized poly(arylene ether ketone) anion exchange membrane for water electrolysis with improved chemical stability," Journal of Membrane Science, vol. 581, pp. 139-149, 2019.

[34] G. Li, C. Zhao, C. Zhu et al., "Side-chain-type quaternized naphthalene-based poly (arylene ether ketone) $s$ for anhydrous high temperature proton exchange membranes," RSC Advances, vol. 6, no. 101, pp. 98854-98860, 2016.

[35] L. Lin, Z. Chen, Z. Zhang et al., "New comb-shaped ionomers based on hydrophobic poly(aryl ether ketone) backbone bearing hydrophilic high concentration sulfonated micro-cluster," Polymer, vol. 96, pp. 188-197, 2016.

[36] D. Liu, Y. Xie, S. Li et al., "High dimensional stability and alcohol resistance aromatic poly (aryl ether ketone) polyelectrolyte membrane synthesis and characterization," ACS Applied Energy Materials, vol. 2, no. 3, pp. 1646-1656, 2019.

[37] N. Lee, D. T. Duong, and D. Kim, "Cyclic ammonium grafted poly (arylene ether ketone) hydroxide ion exchange membranes for alkaline water electrolysis with high chemical stability and cell efficiency," Electrochimica Acta, vol. 271, pp. 150$157,2018$.

[38] S. Zhu, Z. Chen, B. Han, G. Wang, Z. Jiang, and S. Zhang, "Novel nanocellular poly (aryl ether ketone) foams fabricated by controlling the crosslinking degree," RSC Advances, vol. 5, no. 64, pp. 51966-51974, 2015.

[39] S. Maity and T. Jana, "Polybenzimidazole block copolymers for fuel cell: synthesis and studies of block length effects on nanophase separation, mechanical properties, and proton conductivity of PEM," ACS Applied Materials \& Interfaces, vol. 6, no. 9, pp. 6851-6864, 2014.

[40] W. Li, X. Guo, and J. Fang, "Synthesis and properties of sulfonated polyimide-polybenzimidazole copolymers as proton exchange membranes," Journal of Materials Science, vol. 49, no. 7, pp. 2745-2753, 2014.

[41] J. Jang, D.-H. Kim, M.-K. Ahn et al., "Phosphoric acid doped triazole-containing cross-linked polymer electrolytes with enhanced stability for high-temperature proton exchange membrane fuel cells," Journal of Membrane Science, vol. 595, p. $117508,2020$. 